\title{
Finite Element Simulation on Punching Shear Behavior of Reinforced Concrete Slabs
}

\author{
A. K. M. Jahangir Alam ${ }^{1}$ and Khan Mahmud Amanat ${ }^{2}$ \\ ${ }^{1}$ Engineering Office, Bangladesh University of Engineering and Technology (BUET), Dhaka 1000, Bangladesh \\ ${ }^{2}$ Department of Civil Engineering, Bangladesh University of Engineering and Technology (BUET), Dhaka 1000, Bangladesh
}

Correspondence should be addressed to A. K. M. Jahangir Alam, alamj@buet.ac.bd

Received 25 July 2012; Accepted 4 September 2012

Academic Editors: D. Huang and I. Smith

Copyright () 2012 A. K. M. J. Alam and K. M. Amanat. This is an open access article distributed under the Creative Commons Attribution License, which permits unrestricted use, distribution, and reproduction in any medium, provided the original work is properly cited.

\begin{abstract}
A finite element simulation for experimental punching shear behavior of reinforced concrete slab is presented in this paper. The numerical simulation is based on previously tested 15 reinforced concrete model slabs. Finite element analysis of reinforced concrete slabs subjected to punching load is evaluated and results are compared with experiments. This study involves development of a nonlinear strategy which implements solution for a realistic description of the deflection, load carrying capacity and crack, pattern related to punching shear of RC slabs for several types of slab thickness, edge restraints, and reinforcement ratio. It has been shown that the load versus. deflection diagram and ultimate load capacity obtained from FE analysis closely match with the experimental results. Comparison of crack pattern of the slab also shows good agreement. It has been shown that using appropriate method and material for numerical simulation, significant benefit can be achieved using finite element tools and advanced computing facilities in obtaining safe and optimum solutions without doing expensive and time-consuming laboratory tests.
\end{abstract}

\section{Introduction}

For the design of punching shear, code provisions rely mostly on empirical methods derived from the test results on simply supported conventional [1] and thin slab specimens [2]. Some of the present-day code provisions usually specify the punching shear strength as a function of concrete strength alone. Thus, these codes do not take adequate account of the possible role of specimen size, edge restraint, as well as effect of longitudinal reinforcement $[3,4]$. Extensive experimental data and analysis using possible role of restraint, effect of reinforcement, and slab thickness should be considered in the code provision. The present study comprised of a planned series of finite element analysis to simulate test results on restrained as well as unrestrained slabs, variation of flexural reinforcement, and slab thickness.

Nonlinear analysis programs have become increasingly popular in recent years as engineers attempt to more realistically model the behavior of structures subjected to all types of loading [5]. Computer simulation makes the accuracy for describing actual behavior of structure, compare the behavior with laboratory experimenting methods, prospects in the process of scientific research, and relation with experiment and analysis methods. Nonlinear-layered finite element method is capable of analyzing cracking and punching shear failure of reinforced concrete flat plates with spandrel beams or torsion strips $[6,7]$. It is very important that before practical application finite element analysis methods should be verified and validated comparing the analysis results with reliable experiment data.

In this paper, a numerical simulation for experimental punching shear behaviors of reinforced concrete slabs has been developed based on previous experimental studies [3]. This simulation of experimental model has been incorporated into a nonlinear finite element analysis program. The numerical simulations using for reinforced concrete slabs were based on the total strain crack model approach $[8,9]$. This study involves the development of a nonlinear strategy which implements solution for a realistic description of the deflection, load capacity, and crack process related to punching shear of RC slabs for several type of slab thickness, edge restraints, and reinforcement ratio. The simulation would 
investigate experimental behavior of structural concrete slabs under different loadings and it is thought that the findings would be useful in structural design works.

\section{Experimental Procedure}

The experimental result is briefly discussed in this paper. Full details can be found in the published research paper of this author [3]. The basic parameters needed for numerical analysis are shortly discussed below.

2.1. Specimen Details. A total of 15 square reinforced concrete tested slab specimens have been used in this study. The concrete used in the specimens consisted of ordinary Portland cement, natural sand, and crushed stone aggregate with maximum size $10 \mathrm{~mm}$. The water cement ratio for concrete was 0.45 . Both $6 \mathrm{~mm}$ and $10 \mathrm{~mm}$ diameter steel bars having average yield strength of $421 \mathrm{MPa}$ were used in the slab panels and stirrup of edge beams. Flexural reinforcements in the edge beam were provided by $16 \mathrm{~mm}$ diameter deformed steel bars with average yield strength $414 \mathrm{MPa}$. Details of the slab samples are accumulated in Table 1 and typical plan, sectional details of slabs with edge beam and reinforcement placements are shown on the Figure 1.

2.2. Testing Procedure. Four steel blocks were used at each corner of the slab as support. These blocks confirmed the clear span of $1200 \mathrm{~mm}$ of all samples and support of edge beam. During testing, corner sides of each sample were properly anchored by means of heavy joist, which was connected to structural floor. There was one LVDT at the midspan to measure the central slab deflection; one LVDT was placed at the middle span of one of the edge beams to measure the central vertical deflection of the edge beam and four LVDTs at the corner of edge beams to assess the performance of the supports. Loading was applied to specimen at an approximately constant rate up to the peak load, at the same time deflections were measured. Failure occurred abruptly in all specimens and loading was stopped after failure.

2.3. Discussion on Test Results. All the models underwent punching type of failure with their inherent brittle characteristics. The cracking pattern of the top surface of all the slabs was much localized and approximately had a size of $120 \mathrm{~mm} \times 120 \mathrm{~mm}$ (size of loading block). The cracking patterns at the bottom surface of slabs having low percentage of reinforcement were more severe than those having higher percentages of steel. It has also been observed for all the samples that the deflection at support was negligible, pointing out to the fact that support fixity was ensured, albeit approximately, during the testing of the models. A typical crack pattern after failure on the top surface of slab model is shown on Figure 2, which was common for all slabs. It has been found that ultimate punching shear capacity and behavior of slab samples are dependent on restraining action of slab edges [10], flexural reinforcement ratio [11, 12], slab thickness and span-to-depth ratio of the slab $[3,13]$.
Central slab deflections were smaller for the slabs restrained by edge beams. The value of deflection decreased, in general, as the degree of edge restraint increased. Deflection is also very close in same thickness of slab with different reinforcement ratio. Cracking on the underside of the slabs developed as a series of cracks radiating from the centrally loaded area. As the load increased, the widths of the cracks increased.

For lower level of reinforcement ( $\rho=0.5$ percent), numbers of cracks were small and more spalling occurred than others. For higher level of flexural reinforcement $(\rho=1.5$ percent), cracks were concentrated in the middle portion of the slab. Cracking pattern were fine and large in number in case of strongly restrained slabs (SLAB1 to SLAB6), for moderately restrained slabs such cracks were found to be wider and fewer in number. On the other hand, in slab having lesser amount of lateral restraint, initially produced cracks could widen and thereby, the total energy was distributed to lesser but wider cracks.

\section{Finite Element Modelling of Tested Specimens}

3.1. General. The modeling of a concrete structure, which has to be analyzed, can be divided into three major parts: (i) the modeling of the geometry of structure, selection of appropriate element, and proper finite element meshing; (ii) the modeling of the physical behavior of the materials which are applied in the structure, for instance concrete and reinforcing steel; (iii) the modeling of the structural effects which influence the behavior of the structure, for instance large displacements.

In this study, the finite element software DIANA developed by TNO DIANA BV [14] was used to develop finite element model of concrete slabs. In this paper, it was decided to focus on modeling both the load deflection characteristics of the slabs and cracking. Stress-strain behavior of a typical slab model, which was not included in the experiment, is also discussed.

3.2. Element Selection. The elements adopted were twentynode isoparametric solid brick element (elements CHX60). The element is based on quadratic interpolation and Gauss integration. The basic variables at the nodes of this element are the translations in the local element directions. This element approximates that the strain $\varepsilon_{x x}$ and stress $\sigma_{x x}$ vary linearly in $x$ direction and quadratically in $y$ and $z$ direction over the element volume. Distribution of strain $\varepsilon_{y y}$ and $\varepsilon_{z z}$, stress $\sigma_{y y}$ and $\sigma_{z z}$ follow similar approximation.

Gaussian $3 \times 3 \times 3$ integration scheme was used which yields optimal stress points. The Green-Lagrange strains are derived for all integration points and may be extrapolated to the nodes. The most important feature of this element is that it can represent both linear and nonlinear behavior of the concrete. For the linear stage, the concrete is assumed to be an isotropic material up to cracking. For the nonlinear part, the concrete may undergo plasticity and/or creep. 
TABLe 1: Specimen details.

\begin{tabular}{|c|c|c|c|c|c|c|}
\hline Slab sample & $\begin{array}{l}\text { Slab thickness }(h) \\
\text { mm }\end{array}$ & $\begin{array}{c}\text { Cylinder strength } \\
\left(f_{c}^{\prime}\right) \\
\mathrm{MPa}\end{array}$ & $\begin{array}{c}\text { Reinforcement } \\
\text { ratio }(\rho) \\
\%\end{array}$ & $\begin{array}{c}\text { Bottom rod in } \\
\text { each direction } \\
\text { No.-mm } \phi\end{array}$ & $\begin{array}{l}\text { Width of stiff } \\
\text { edge beam }(b) \\
\text { mm }\end{array}$ & $\begin{array}{c}\text { Reinforcement in } \\
\text { edge beam } \\
\text { No.-mm } \phi\end{array}$ \\
\hline SLAB1 & 80 & 38.51 & 0.5 & $15-6$ & 245 & $4-16$ \\
\hline SLAB2 & 80 & 37.42 & 1.0 & $30-6$ & 245 & $4-16$ \\
\hline SLAB3 & 80 & 28.19 & 1.5 & $16-10$ & 245 & $4-16$ \\
\hline SLAB4 & 60 & 38.24 & 0.5 & $11-6$ & 245 & $4-16$ \\
\hline SLAB5 & 60 & 36.60 & 1.0 & $22-6$ & 245 & $4-16$ \\
\hline SLAB6 & 60 & 41.95 & 1.5 & $33-6$ & 245 & $4-16$ \\
\hline SLAB7 & 80 & 32.45 & 1.0 & $30-6$ & 175 & $4-16$ \\
\hline SLAB8 & 60 & 41.30 & 0.5 & $11-6$ & 175 & $4-16$ \\
\hline SLAB9 & 60 & 33.14 & 1.0 & $22-6$ & 175 & $4-16$ \\
\hline SLAB10 & 80 & 37.45 & 1.0 & $30-6$ & 105 & $4-16$ \\
\hline SLAB11 & 60 & 40.43 & 0.5 & $11-6$ & 105 & $4-16$ \\
\hline SLAB12 & 60 & 37.04 & 1.0 & $22-6$ & 105 & $4-16$ \\
\hline SLAB13 & 80 & 37.72 & 1.0 & $30-6$ & - & $* 3-16$ \\
\hline SLAB14 & 60 & 34.71 & 0.5 & $11-6$ & - & $* 3-16$ \\
\hline SLAB15 & 60 & 33.03 & 1.0 & $22-6$ & - & $* 3-16$ \\
\hline
\end{tabular}

* Slabs were extended outward by $175 \mathrm{~mm}$ and these reinforcements were provided at bottom layer.

All stirrups for edge beam were $6 \mathrm{~mm} \phi$ at $88 \mathrm{~mm} \mathrm{c} / \mathrm{c}$., clear span $=1200 \mathrm{~mm}$.

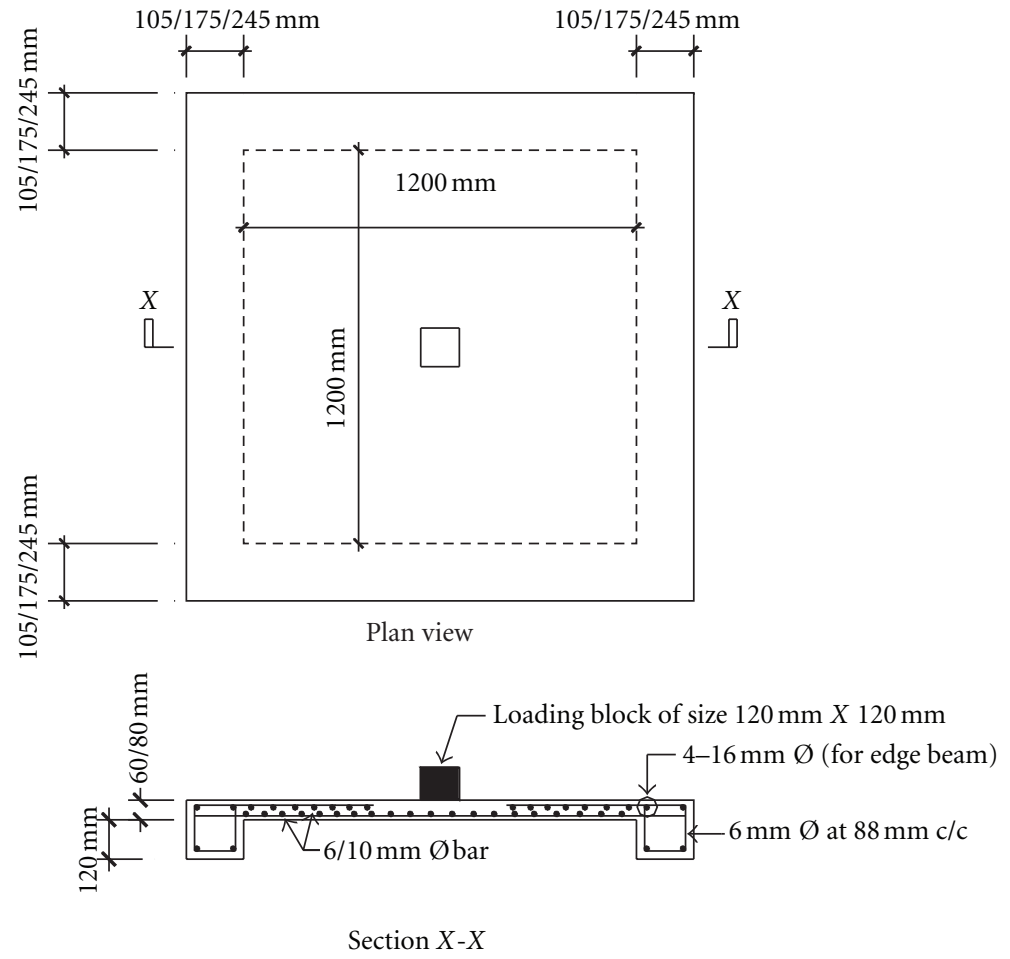

FIGURE 1: Details of a typical model slab with reinforcement.

3.3. Material Model of Concrete. The constitutive behavior of concrete material is characterized by tensile cracking and compressive crushing, yielding of the reinforcement. Total strain crack model was adopted for this study. A total strain approach is used with fixed smeared cracking [15]; that is, the crack direction is fixed after crack initiation. For this approach, a compression and a tension stress-strain curve are used.
The constitutive model based on total strain is developed along the lines of the Modified Compression Field Theory, originally proposed by Vecchio and Collins [8]. The threedimensional extension to this theory was proposed by Selby and Vecchio [9] and was followed during the implementation in analysis.

The input for the total strain crack models comprises two parts: (1) the basic properties like the Young's modulus, 


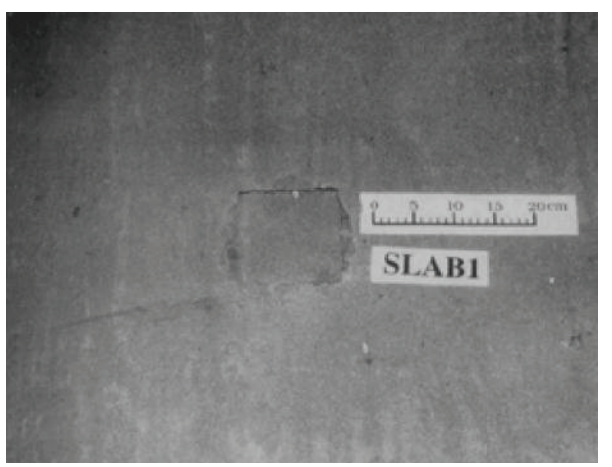

FIGURE 2: Typical cracking pattern on the top surface of a model slab.

Poisson's ratio, tensile, and compressive strength, and so forth and (2) the definition of the behavior in tension, shear, and compression. Mohr Coulomb yield criterion is used in the present analysis.

3.3.1. Compressive Behavior. The compressive behavior is in general a nonlinear function between the stress and the strain in a certain direction. Concrete subjected to compressive stresses shows a pressure-dependent behavior, that is, the strength and ductility increase with increasing isotropic stress. Due to the lateral confinement, the compressive stressrelationship is modified to incorporate the effects of the increased isotropic stress.

The base function in compression can be modeled with a number of different predefined and user-defined curves. The predefined curves are the constant curve and the brittle curve, and the linear and exponential softening curves based on the compressive fracture energy. The linear hardening and the saturation hardening curves are available. The available hardening-softening curves in compression are the parabolic, the parabolic-exponential, and the hardening curve according to Thorenfeldt et al. [16]. The predefined compressive constant curve is used in the present study.

3.3.2. Tensile Behavior. For the total strain crack model, four softening functions based on fracture energy are implemented, a linear softening curve, an exponential softening curve, the nonlinear softening curve according to Reinhardt [17], and the nonlinear softening curve according to Hordijk [18]. A constant tensile behavior, a multilinear behavior, and a brittle behavior can also implemented in model. The nonlinear tension softening curve according to Hordijk [18] is used in the present study.

3.3.3. Shear Behavior. The modeling of the shear behavior is only necessary in the fixed crack concept where the shear stiffness is usually reduced after cracking. A constant shear retention factor $=0.2$ was considered for the reduction of shear stiffness of concrete due to cracking.

3.4. Modeling of Slab Geometry. Due to the balance of energy, failure occurs symmetrically in symmetric model. But in

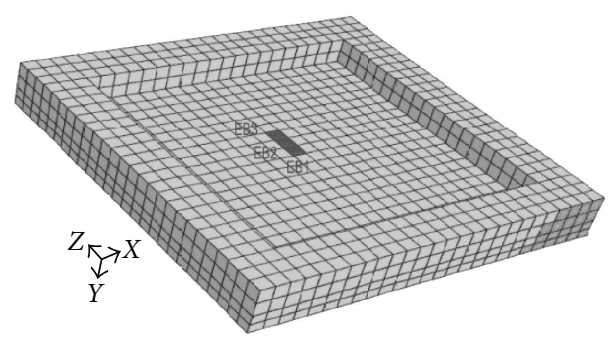

Figure 3: Meshed model of a typical slab showing bottom surface.

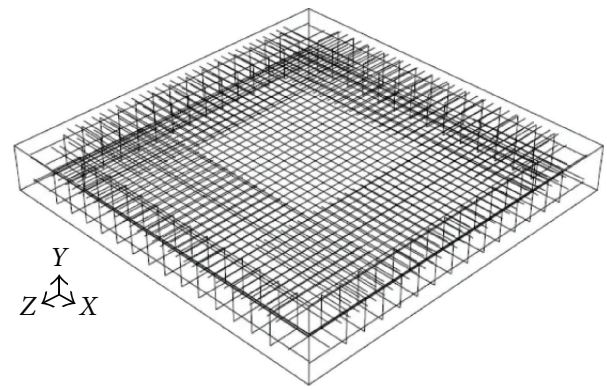

FIGURE 4: Embedded reinforcement in a typical slab model.

actual experiment, failure does not occur symmetrically in symmetric model. Thus, full-scale geometry of all slabs was modeled by using the finite element program and meshed model of a typical slab is shown in Figure 3. Elements EB1, EB2, and EB3 shown in Figure 3 are individual element at central region of slab, analytical result of which are used for $\mathrm{FE}$ analysis. Element EB1 is located at the central bottom surface of slab model, whereas element EB1 and EB2 are $90 \mathrm{~mm}$ and $150 \mathrm{~mm}$ apart from slab center, respectively. Element ET1, ET2, and ET3 are located at the central top surface of slab model, geometrically opposite side of EB1, EB2, and EB3, respectively.

3.5. Reinforcement Model. The reinforcement mesh in a concrete slab was modeled with the bar reinforcement embedded in the solid element. In finite element mesh, bar reinforcements have the shape of a line, which represents actual size and location of reinforcement in the concrete slab and beam. Thus in the present study, reinforcements are used in a discrete manner exactly as they appeared in the actual test specimens. The constitutive behavior of reinforcement modeled by elastoplastic material model with hardening. Tension softening of the concrete and perfect bond between the bar reinforcement and the surrounding concrete material was assumed. This was considered reasonable since welded mesh reinforcement was used in the tests. Typical reinforcement in finite element model is shown in Figure 4. The steel reinforcement behaves elastically up to the Von Mises yield stress of $421 \mathrm{MPa}$ for slab and $414 \mathrm{MPa}$ for edge beam.

3.6. Boundary Condition. The edge beams of the slab were vertically restrained at four corners, as in the experimental setup. To prevent the slab from moving and rotating in its 

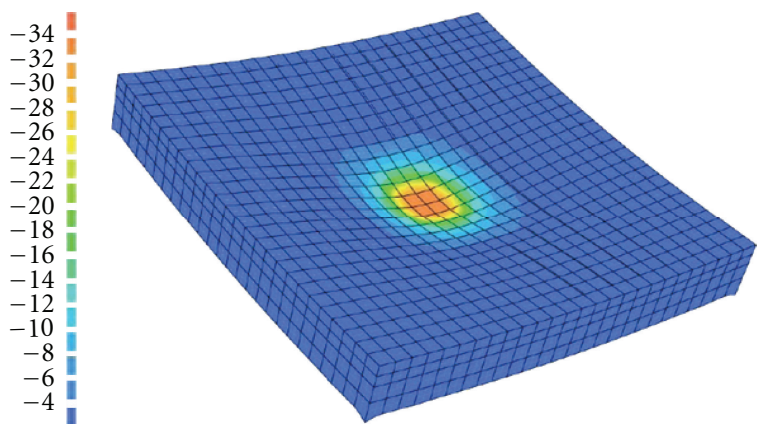

(a)
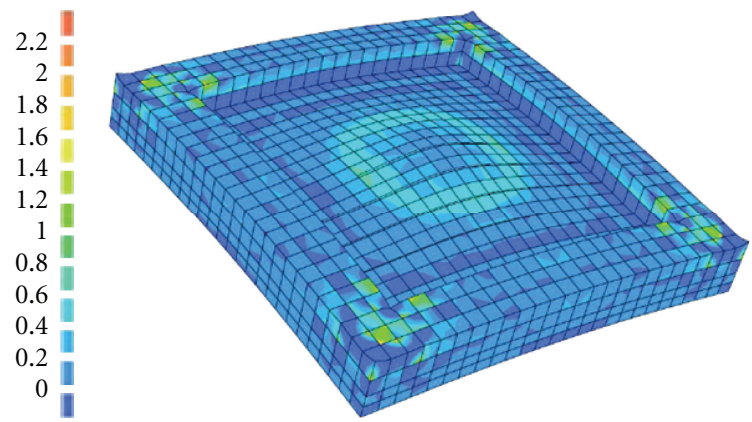

(b)

Figure 5: Deflected shape and stress contour shown on (a) top surface and (b) bottom surface of typical slab model.

own plane, one corner had all translation degrees of freedom fixed, while diagonally opposite of that corner was fixed with two degrees of freedom.

3.7. Loading. Loading was applied within at $120 \mathrm{~mm} \times$ $120 \mathrm{~mm}$ area of central portion of slab model at the top surface to simulate actual experimental loading.

3.8. Solving Strategy. A commonly used modified NewtonRaphson solving strategy was adopted, incorporating the iteration based on conjugate gradient method with arclength control. The line search algorithm for automatically scaling the incremental displacements in the iteration process was also included to improve the convergence rate and the efficiency of analyses. Second order plasticity equation solver solved physical nonlinearity with total strain cracking. Reinforcement was evaluated in the interface elements. Accuracy was checked by the norms of residual vector.

\section{Results of FE Analysis}

The main target of this study is to compare results of finite element analysis with the actual experimental investigation. Thus, analysis results were accumulated in the same manner as experimental test results. Typical deflected shape and stress contour of slab model is shown in Figure 5. Experimental failure on top surface of slab model as shown in Figure 2 was very localized which is represented analytically by stress contour on top surface as shown in Figure 5(a).

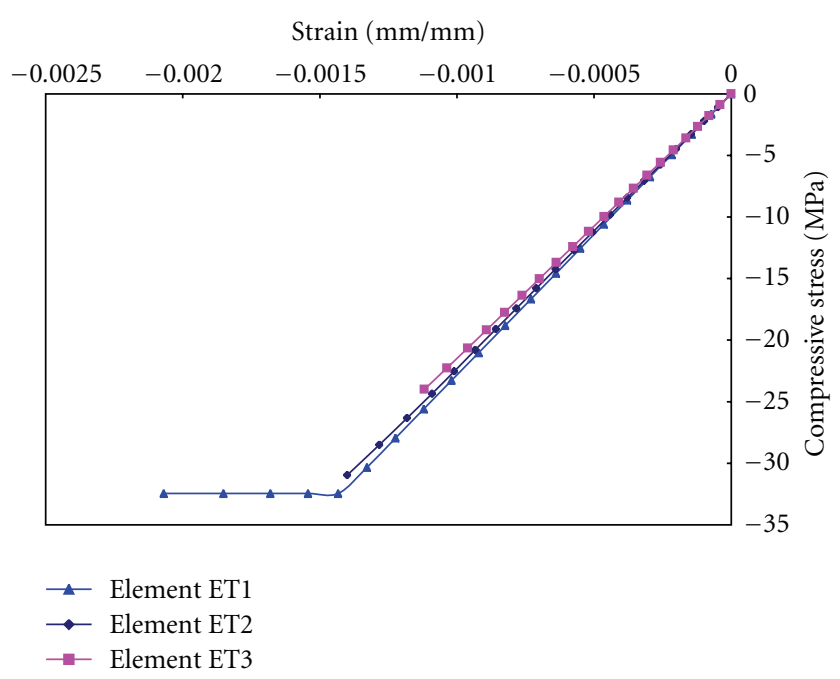

Figure 6: Compressive stress-strain on top surfaces of typical slab.

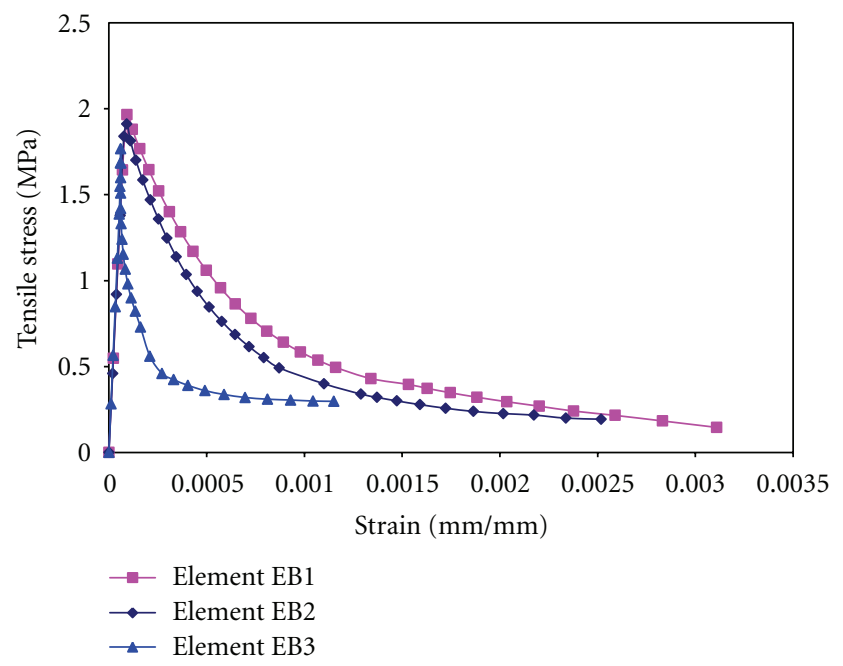

FIgURE 7: Tensile stress-strain on bottom surfaces of typical slab.

Compressive stress developed on top surface and tensile stresses developed on bottom surface at the central region of slab are shown in Figure 5. Maximum compressive stresses were produced on top surface, which are concentrated around and within the loading block. But higher value of tensile stress developed outside of the loading block as shown in Figure 5(b) and indicative to failure surface at that portion. This analytical stress concentration at bottom surface as shown in Figure 5 are analogous to experimental failure surface as well as cracking pattern of slabs.

Stress-strain curve of concrete is shown in Figures 6 and 7. In Figure 6, related stress and strain are calculated at the integration point positioned on the top face of slab. Concrete failed by compression at central region on top surfaces (element ET1) earlier than apart from center as shown in Figure 6. In Figure 7, related stress and strain are calculated at the integration point positioned on the bottom face of slab. Higher strain at same tensile stress obtained on central region 


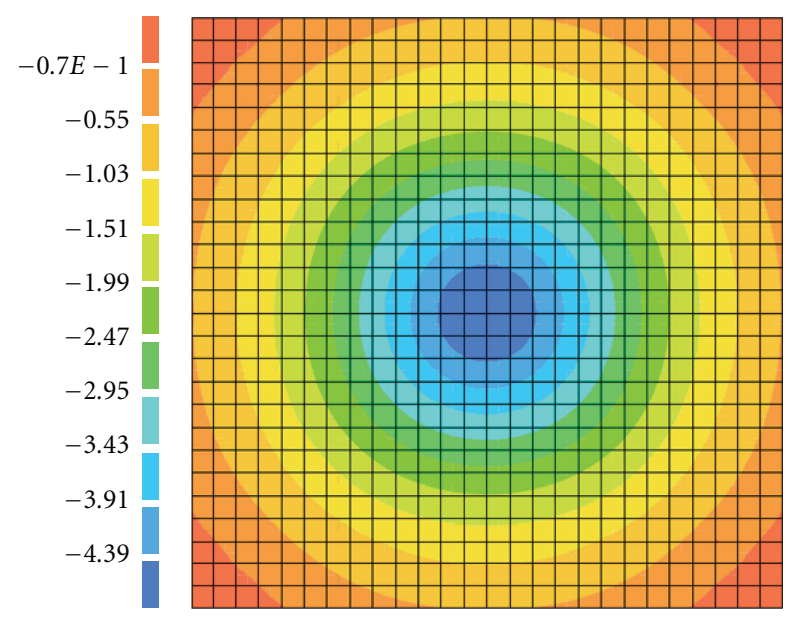

FIGURE 8: Deflection contour of bottom surface of a typical slab.

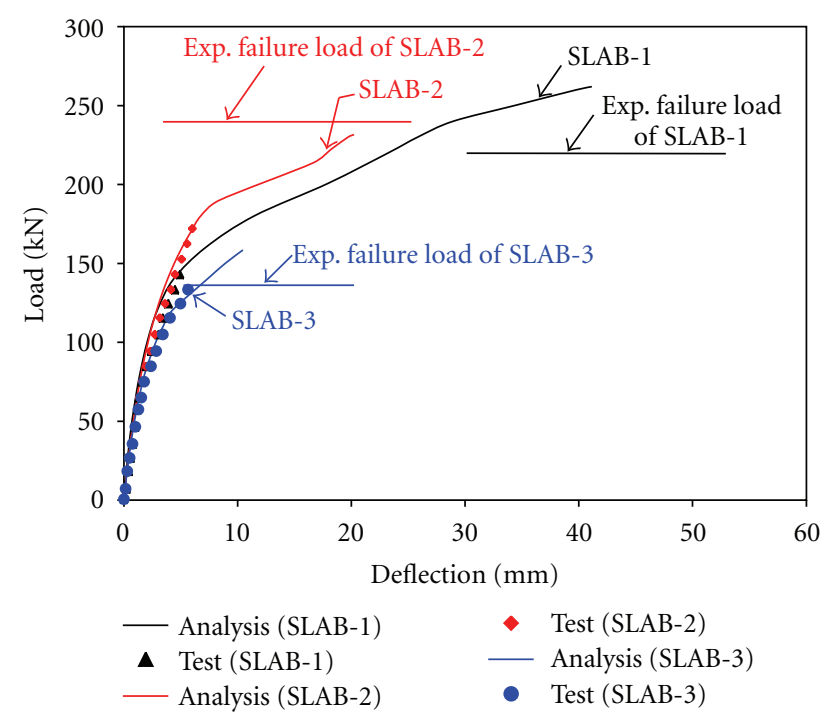

Figure 9: Load-deflection curves of analyzed and tested model having slab thickness $=80 \mathrm{~mm}$ and width of edge beam $=245 \mathrm{~mm}$.

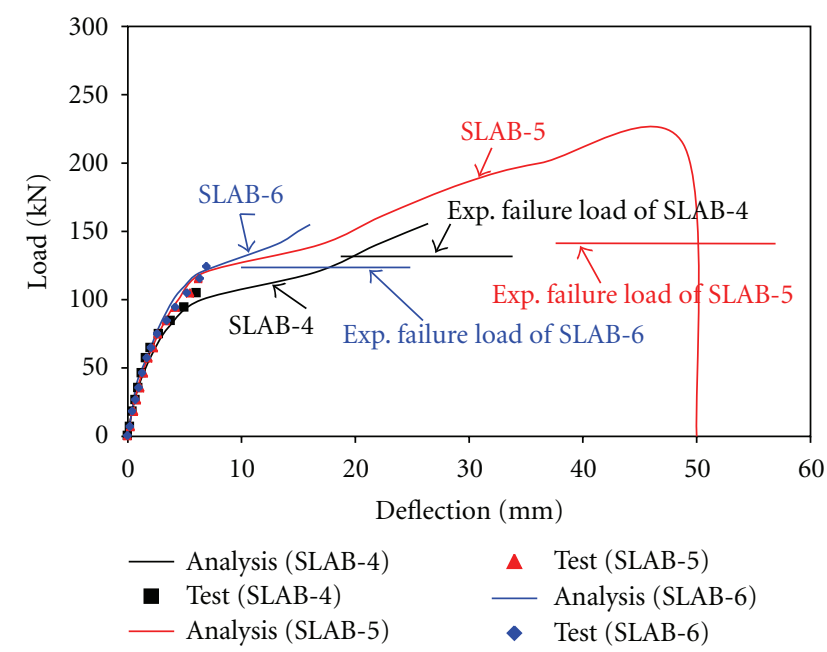

FIGURE 10: Load-deflection curves of analyzed and tested model having slab thickness $=60 \mathrm{~mm}$ and width of edge beam $=245 \mathrm{~mm}$.

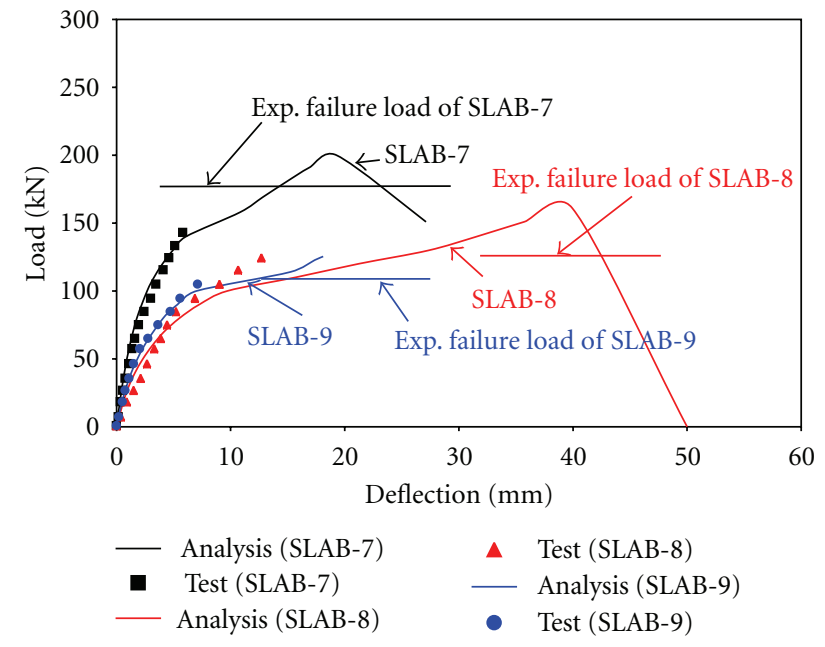

FIGURE 11: Load-deflection curves of analyzed and tested model having width of edge beam $=175 \mathrm{~mm}$.

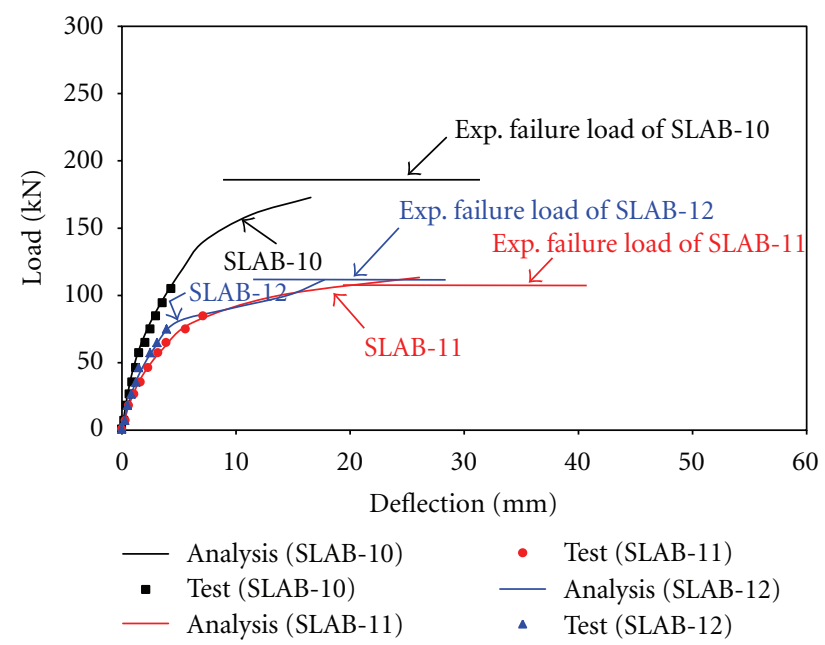

Figure 12: Load-deflection curves of analyzed and tested model having width of edge beam $=105 \mathrm{~mm}$.

on bottom surface (element EB1) in comparison to others. The higher the strain, the higher the crack width produced there. Stress-strain of typical embedded reinforcement at central zone of slab is linear. It is to note that reinforcements at bottom surface of slab remain elastic and tensile strength is much lesser than yield strength of steel, thus failure of steel does not occur here. Deflection contour for a specific applied load is also shown in Figure 8. Deflection of slab decreases gradually from center toward the edge beam as shown in Figure 8.

\section{Comparison of FE Analysis with Test Result}

5.1. Load-Displacement Curve. It may be recalled that complete load-deflection curves of the entire slab tested could not be traced due to limitation of available instruments. For the finite element analysis the load-displacement response 


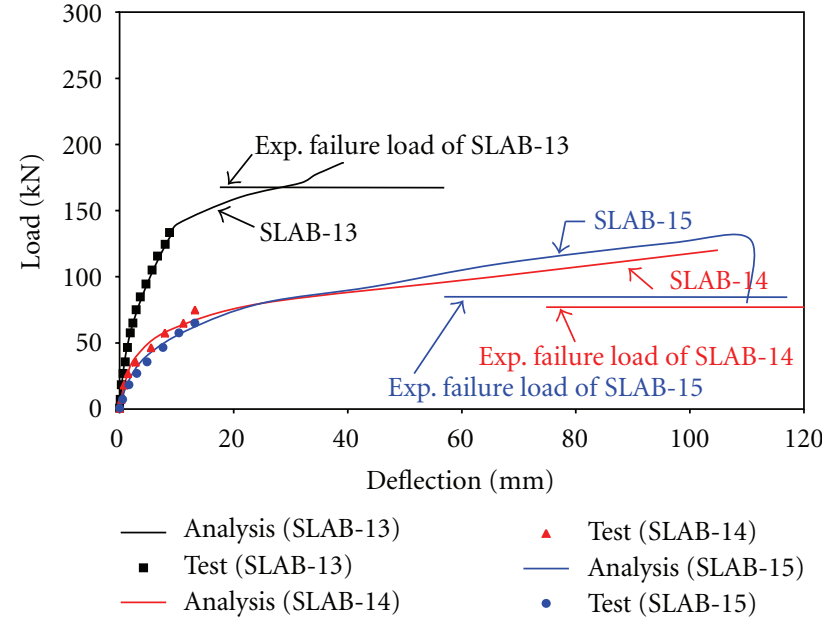

Figure 13: Load-deflection curves of analyzed and tested model having no edge beam.

can be predicted over the full history of the analysis. For comparison purpose, analytical value of applied load and respective deflection have taken same way as experimental value of each slab model. Load deflection curve for all $15 \mathrm{slab}$ models are compared by four groups depending upon the width of edge beam. Figures 9 and 10 show load deflection behavior of SLAB-1 to SLAB-6 having $245 \mathrm{~mm}$ width of edge beam. Similarly Figures 11 and 12 show load deflection curves for width of edge beam $175 \mathrm{~mm}$ and $105 \mathrm{~mm}$, respectively. Figure 13 shows load deflection behavior for SLAB13, SLAB-14, and SLAB-15, which have no stiff edge beam.

It is clear from Figures 9 to 13 that analytical load deflection behavior of all model slabs are matched with experimental result. In case of same width of edge beam, variation of deflection occurred due to the variation of slab thickness and reinforcement ratio. It is obvious that edge restraint and tensile reinforcement play a significant role in the behavior of RC slab subjected to punching force. Similar trend of load deflection behavior of numerical analysis and experimental data is indicative for similar nature of other parameters for structural designing of slab.

5.2. Ultimate Load Capacity. Failure load in both experiment and analysis are very close in most of the slab models. If the same FE model is used for similar types of slab, the punching load capacity of that slab may be predicted. Thus, significant benefit can be achieved in obtaining safe and optimum solutions of structure in punching.

5.3. Crack Pattern. Figure 14 shows the crack pattern of finite element model of a typical slab for applied load of $180 \mathrm{kN}$, where uniaxial principal strain characteristics is used. Cracks at the bottom surface are propagated toward edge beam and major cracking area is concentrated to central region of slab. The major cracking produced a circular bounded area in both analysis and experiment.

The trend and area of cracking are also similar as shown in Figures 15 and 16, where similar grid line is inserted

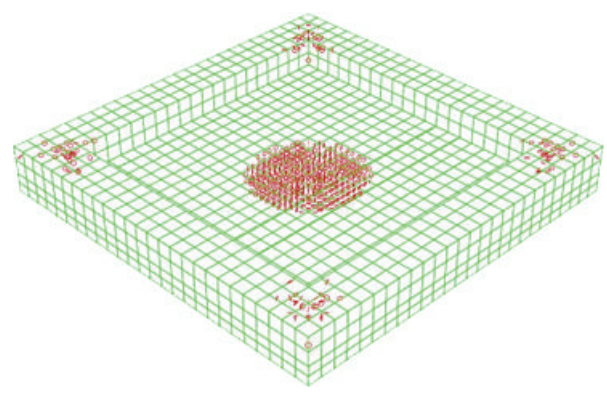

Figure 14: Cracking pattern of a typical slab at bottom surface.

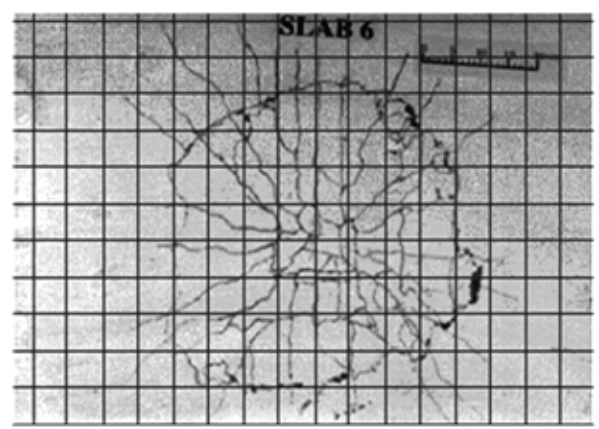

(a)

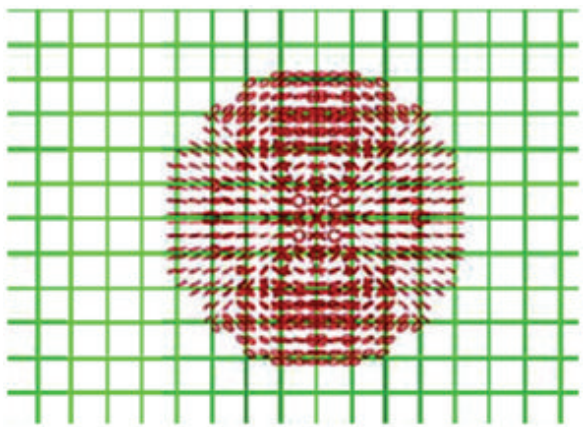

(b)

FIgure 15: Cracking at bottom surface of SLAB6 showing (a) experimental cracking pattern, (b) analytical cracking pattern.

on experimental cracked slab to compare with analytical cracking area. Cracking area is smaller in case of strongly restrained slabs. For comparatively smaller restrained slab such area is increased accordingly as shown in Figures 15 and 16.

\section{Conclusions}

Comparing numerical simulation of 15 model slab with experimental results, the following conclusions can be drawn considering the facts found in this study.

(a) Load verses deflection diagram has been reasonably simulated using finite element model. In finite element simulation, the load-displacement response can 


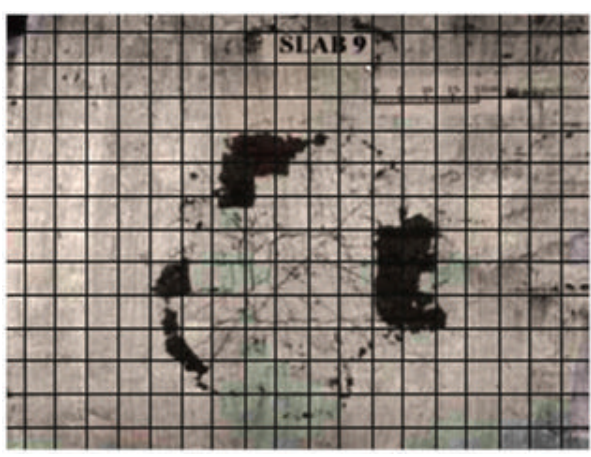

(a)

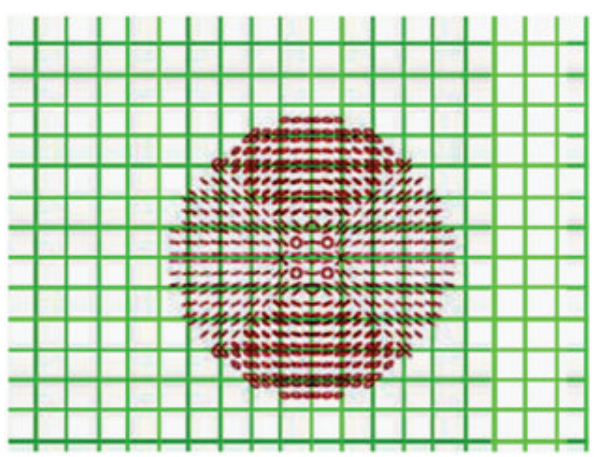

(b)

FIGURE 16: Cracking at bottom surface of SLAB9 showing (a) experimental cracking pattern, (b) analytical cracking pattern.

be predicted over the full history of the analysis. Punching failure load can also be predicted in FE analysis.

(b) Cracking in an important phenomenon on punching shear behavior of reinforcement concrete slab. Such cracking area and pattern of cracking can be effectively simulated by numerical analysis.

(c) Numerical simulation based on nonlinear finite element analysis for punching shear behavior of reinforced concrete slabs can effectively be used which reasonably simulate the actual behavior and provide a virtual testing scheme of structures to explore their behavior under different loadings and other effects under different conditions.

(d) Using appropriate method and material for numerical simulation, it can be demonstrated that significant benefits can be achieved using finite element tools and advanced computing facilities to obtain safe and optimum building solutions without the need for expensive and time-consuming laboratory testing.

(e) The validated finite element analysis model is a suitable and reliable research tool for further detailed numerical investigations of reinforced concrete slabcolumn connection behavior for punching shear.

\section{Notations}

$b$ : $\quad$ Width of edge beam, $\mathrm{mm}$

$d: \quad$ Effective depth of reinforcement, $\mathrm{mm}$

$f_{c}^{\prime}$ : $\quad$ Cylinder compressive strength of concrete, $\mathrm{MPa}$

$f_{y}: \quad$ Yield strength of reinforcement, $\mathrm{MPa}$

$h: \quad$ Slab thickness, $\mathrm{mm}$

$\rho: \quad$ Reinforcement ratio, \%

$\varepsilon_{x x}, \varepsilon_{y y}, \varepsilon_{z z}:$ Principal strain, $\mathrm{mm} / \mathrm{mm}$

$\sigma_{x x}, \sigma_{y y}, \sigma_{z z}$ : Principal stress, MPa.

\section{References}

[1] W. Salim and W. M. Sebastian, "Punching shear failure in reinforced concrete slabs with compressive membrane action," ACI Structural Journal, vol. 100, no. 4, pp. 471-479, 2003.

[2] J. S. Lovrovich and D. I. McLean, "Punching shear behavior of slabs with varying span-depth ratios," ACI Structural Journal, vol. 87, no. 5, pp. 507-511, 1990.

[3] A. K. M. J. Alam, K. M. Amanat, and S. M. Seraj, "Experimental investigation of edge restraint on punching shear behaviour of RC slabs," The IES Journal Part A, vol. 2, no. 1, pp. 35-46, 2009.

[4] J. S. Kuang and C. T. Morley, "Punching shear behavior of restrained reinforced concrete slabs," ACI Structural Journal, vol. 89, no. 1, pp. 13-19, 1992.

[5] M. B. D. Hueste and J. K. Wight, "Nonlinear punching shear failure model for interior slab-column connections," Journal of Structural Engineering, vol. 125, no. 9, pp. 997-1008, 1999.

[6] W. Wang and S. Teng, "Finite-element analysis of reinforced concrete flat plate structures by layered shell element," Journal of Structural Engineering, vol. 134, no. 12, pp. 1862-1872, 2008.

[7] Y. C. Loo and H. Guan, "Cracking and punching shear failure analysis of RC flat plates," Journal of Structural Engineering, vol. 123, no. 10, pp. 1321-1330, 1997.

[8] F. J. Vecchio and M. P. Collins, "The modified compression field theory for reinforced concrete elements subjected to shear," Journal of the American Concrete Institute, vol. 83, no. 2, pp. 219-231, 1986.

[9] R. G. Selby and F. J. Vecchio, "Three-dimensional constitutive relations for reinforced concrete,” Tech. Rep. 93-02, University of Toronto, Department of Civil Engineering, Toronta, Canada, 1993.

[10] C. G. Bailey, W. S. Toh, and B. M. Chan, "Simplified and advanced analysis of membrane action of concrete slabs," $A C I$ Structural Journal, vol. 105, no. 1, pp. 30-40, 2008.

[11] W. Dilger, G. Birkle, and D. Mitchell, "Effect of flexural reinforcement on punching shear resistance," in Punching Shear in Reinforced Concrete Slabs, SP-232-4, pp. 57-74, American Concrete Institute, 2005.

[12] N. J. Gardner, "ACI 318-05, CS A23.3-04, eurocode 2 (2003), DIN 1045-1 (2001), BS 8110-97 and CEB-FIP MC 90 provisions for punching shear of reinforced concrete flat slabs," in Punching Shear in Reinforced Concrete Slabs, SP-232-1, pp. 122, American Concrete Institute, 2005.

[13] Y. Tan and S. Teng, "Interior slab-rectangular column connections under biaxial lateral loading," in Punching Shear in Reinforced Concrete Slabs, SP-232-9, pp. 147-174, American Concrete Institute, 2005. 
[14] TNO DIANA BV, DIANA Finite Element Analysis User's Manual Release 8.1, TNO DIANA BV, Delft, The Netherlands, 2nd edition, 2003.

[15] H. Hofmeyer and A. A. van den Bos, "Total strain fe model for reinforced concrete floors on piles," Structural Design of Tall and Special Buildings, vol. 17, no. 4, pp. 809-822, 2008.

[16] E. Thorenfeldt, A. Tomaszewicz, and J. J. Jensen, "Mechanical properties of high-strength concrete and applications in design," in Proceedings of the Symposium on Utilization of High-Strength Concrete (Stavanger, Norway), Tapir, Trondheim, Norway, 1987.

[17] H. W. Reinhardt, "Fracture mechanics of an elastic softening material like concrete," Heron, vol. 29, no. 2, 1984.

[18] D. A. Hordijk, Local approach to fatigue of concrete [Ph.D. thesis], Delft University of Technology, 1991. 

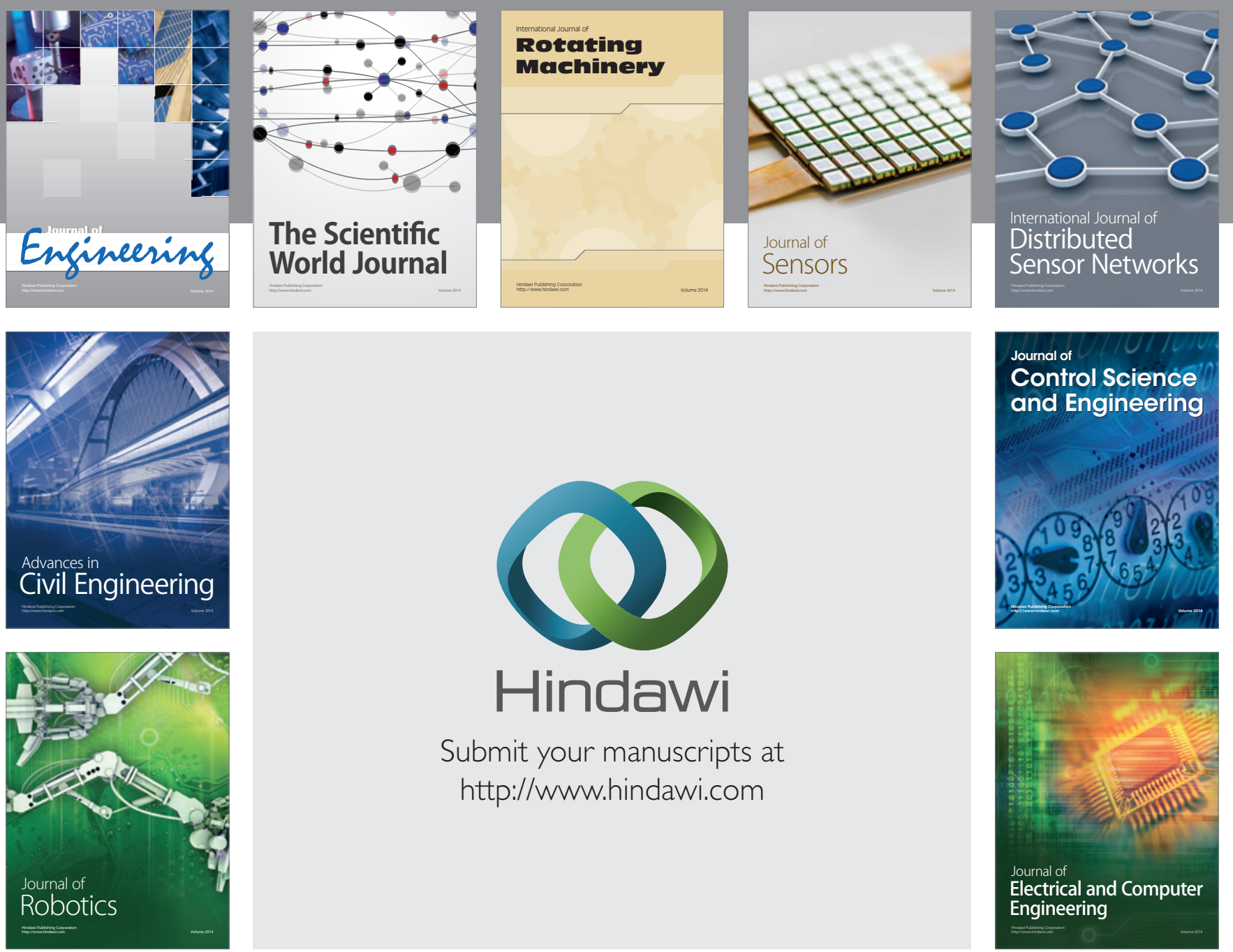

Submit your manuscripts at

http://www.hindawi.com
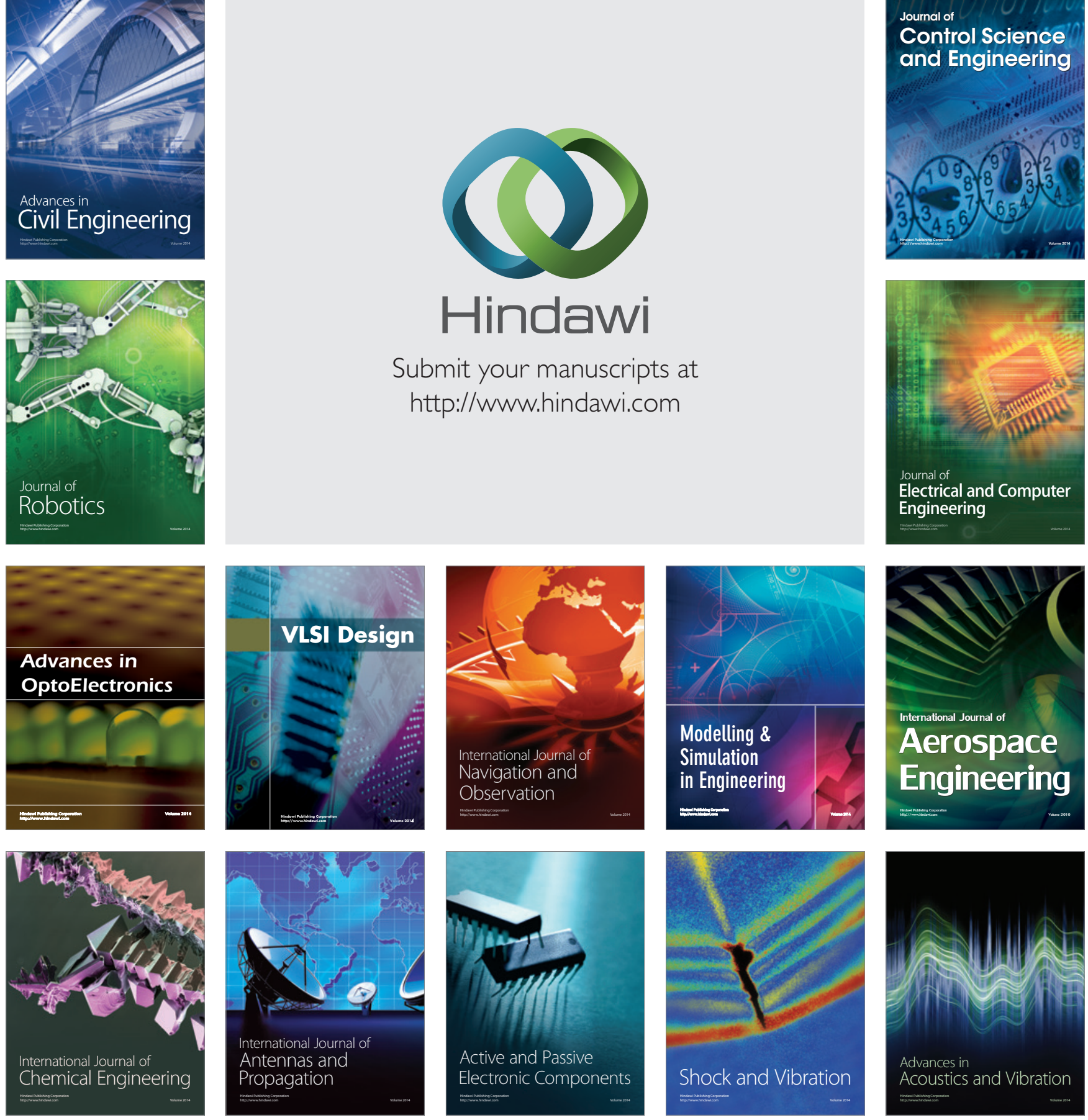